\title{
Religiosidad y espiritualidad del municipio de Santiago Nonualco
}

\author{
Religiousness y and spirituality in the municipality \\ of Santiago Nonualco
}

Carlos Osegueda'

Docente y coordinador de la Licenciatura en Antropología, Escuela de Antropología, Utec

carlos.osegueda@.utec.edu.sv

Recibido: 10/06/2015 - Aceptado: 17/07/2015

\section{Resumen}

La Antropología, como parte de la gran familia de las Ciencias Sociales, contribuye con una serie de procesos metodológicos para la generación de nuevos conocimientos desde las vivencias culturales. En el desarrollo del proyecto "Religiosidad y espiritualidad del municipio de Santiago Nonualco" surge el presente artículo, titulado "Religiosidad y espiritualidad del municipio de Santiago Nonualco. Experiencia investigativa y metodológica educativa inédita salvadoreña". En el presente estudio se hizo el énfasis a la religiosidad y espiritualidad del municipio, siendo esto último lo relevante o el punto vital del engranaje entre los procesos de investigación, la metodología participante y los procesos educativos basados en proyectos de aula; y es ahí donde se marca lo inédito de esta práctica metodológica en El Salvador.

\section{Abstract}

This study emphasized the municipality's religiousness and spirituality, being the latter the most relevant point amongst the investigation processes, the participating methodology and the educational processes based on class projects. It is here where its originality is remarked withing the methodological practices in El Salvador.

As a member of the great Social Sciences family, Anthropology contributes through a series of methodological processes in generating new knowledge from cultural experiences.

While developing the project "Religiousness and spirituality in the municipality of Santiago Nonualco," the following article emerged: "Religiousness and spirituality in the municipality of Santiago Nonualco. An unpublished Salvadorean methodologic and investigative educational experience." This project emphasized the religiousness and religiosity of the municipality; the latter being the most relevant point among the investigation processes, the participating methodology, the educational processes based on classroom projects and their implementation. This is what makes this methodological practice in $\mathrm{El}$ Salvador something unprecedented.

Docente y coordinador de la Licenciatura en Antropología, Escuela de Antropología, Universidad Tecnológica de El Salvador. Egresado de la carrera de Maestría en Docencia e Investigación Educativa de la Utec. Correo electrónico carlos.osegueda@utec.edu.sv 


\section{Palabras clave}

Antropología de la educación, antropología de la religión, antropología sociocultural, ritualidad y espiritualidad.

\section{Keywords}

Educational anthropology, anthropology of religion, sociocultural anthropology, ritual and spirituality.

\section{Introducción}

Desde sus inicios los seres humanos han experimentado una serie de necesidades tanto biológicas como espirituales en la búsqueda de su autorrealización como especie. Sin embargo, las prácticas rituales o ceremoniales, como gestación de un proceso de la cultura inmaterial o intangible, estuvieron presentes desde la sociedad en períodos formativos y que a través del tiempo se expresan en los imaginarios colectivos e individuales de la sociedad moderna.

En ese sentido, Malinowski (1993) explica la importancia de la ciencia y las prácticas religiosas de la siguiente manera:

La ciencia nace de la experiencia, la magia está fabricada por la tradición. La ciencia se guía por la razón y se corrige por la observación; la magia, impermeable a ambas, vive en una atmósfera de misticismo. La ciencia está abierta a todos, es decir, es un bien común de toda la sociedad.

De la misma manera, Kottak (1997) añade que en el campo de la antropología, y dentro de sus corrientes teóricas, autores como Edward Burnett Tylor, considerado como uno de los fundadores de la antropología de la religión, manifestó: “La religión nació cuando la gente intentaba comprender las condiciones y eventos que no podía explicar por referencia a la experiencia cotidiana".

Por tanto, es ahí donde cobran gran relevancia los resultados de la presente investigación, titulada "Religiosidad y espiritualidad en el municipio de Santiago Nonualco, dado que se enfocó en el análisis de la religiosidad y espiritualidad, así como todas aquellas prácticas y argumentaciones teóricas que son asumidas y proyectadas en los ámbitos individual y colectivo por los participantes del proceso de investigación, como los sacerdotes, pastores de iglesias evangélicas, las parteras, los curanderos, cofrades, promotores y gestores de la cultura municipal, los funcionarios del concejo municipal, entre otros; en donde lo tangible e intangible codifica el sentido del pertenecer y del ser; que linda con lo mágico, lo religioso y lo profano en el municipio de Santiago Nonualco.

\section{Breve historia del municipio de Santiago Nonualco}

El municipio de Santiago Nonualco se sitúa en el distrito de Zacatecoluca, en el departamento de La Paz, a $50 \mathrm{~km}$ de San Salvador y a 8 de Zacatecoluca; limita al norte y noreste con el municipio de San Pedro Nonualco; al este con San Juan Nonualco y al sureste con los municipios de San Rafael Obrajuelo y Zacatecoluca; al sur con San Luis La Herradura; al oeste con el municipio El Rosario y al nororiente con el municipio de San Pedro Masahuat (Alvarado, 1995).

La fundación de Santiago Nonualco data de la época precolombina. Durante este período la civilización nonualca fue uno de los sitios más importantes del país. En cuanto a su origen etimológico, ha habido un gran debate, puesto que hay diversas palabras de las cuales este puede provenir, sin embargo Larín (2000b), al respecto, nos indica lo siguiente: nonualco proviene del náhuat y significa "lugar de mudos", ya que su prefijo es nonual, "mudo", y el sufijo co, "localidad". Así mismo, se tiene otro significado para la palabra nonualco, y es "Lugar del habla hermoso". Esta última concepción de la palabra aún está en discusión.

Así mismo, Larín (1958) nombra al fray Alonso Ponce, quien se refirió en 1586 al lugar de Santiago Nonualco como un "Gran Pueblo". Para febrero de 1870 obtuvo el título de villa y para el 15 de junio de 1920 recibió el de ciudad (Isam, 1988).

Sabemos que Santiago Nonualco fue un lugar con gran población y buen comercio. Para el año de 1770 existían alrededor de 2.363 habitantes, entre ellos 346 familias indígenas. Al parecer Santiago Nonualco fue rico en la siembra del cacao, superando así hasta los izalcos (Larín, 2000a). En una forma más concisa, podemos decir que en la historia de Santiago Nonualco, en el período de la 
Colonia, se reconocieron a la República de Indios y a la República de Españoles; y se considera que en el año 1594 convivieron con "Ios nonoalcos" españoles que comercian con los indios, "más de quince o veinte españoles"; informa Juan de Pinera que les compran el cacao que tienen (Sosa, 2006).

Podemos hablar de un Santiago Nonualco que fue construido desde la visión geográfica y teológica de la Iglesia católica. De acuerdo con la descripción que nos menciona Ibarra (2001), hubo una visita por parte del arzobispo de Guatemala, Pedro Cortés y Larraz, quien visitó a la entonces provincia de San Salvador, haciendo una descripción de los habitantes nonualqueños; y dice que "ellos gozaban de una gran autonomía, eran personas renuentes a ser asimilados a una cultura colonial". Les adjudica el papel de tener a los españoles y ladinos como usurpadores; en sus tierras los miraban con odio, por ende, eran reacios a todo lo que tenía que ver con lo español, sobre todo a la religión, doctrinas y costumbres. Sin mencionar que a estas personas se les ha tildado de ser sangrientos y a la vez mantener un odio excesivo hacia sus vecinos.

Según Sosa (2006), el arzobispo Cortés y Larraz menciona el siguiente dato importante sobre el indio y la vida cotidiana en Santiago Nonualco: "La gente andaba muy desnuda... nunca salen de necesidad, y miseria; desnudos, mal comidos, durmiendo por el suelo, cargados por los caminos, sin ser dueños de cosa alguna, azotados muy frecuentemente en las picotas".

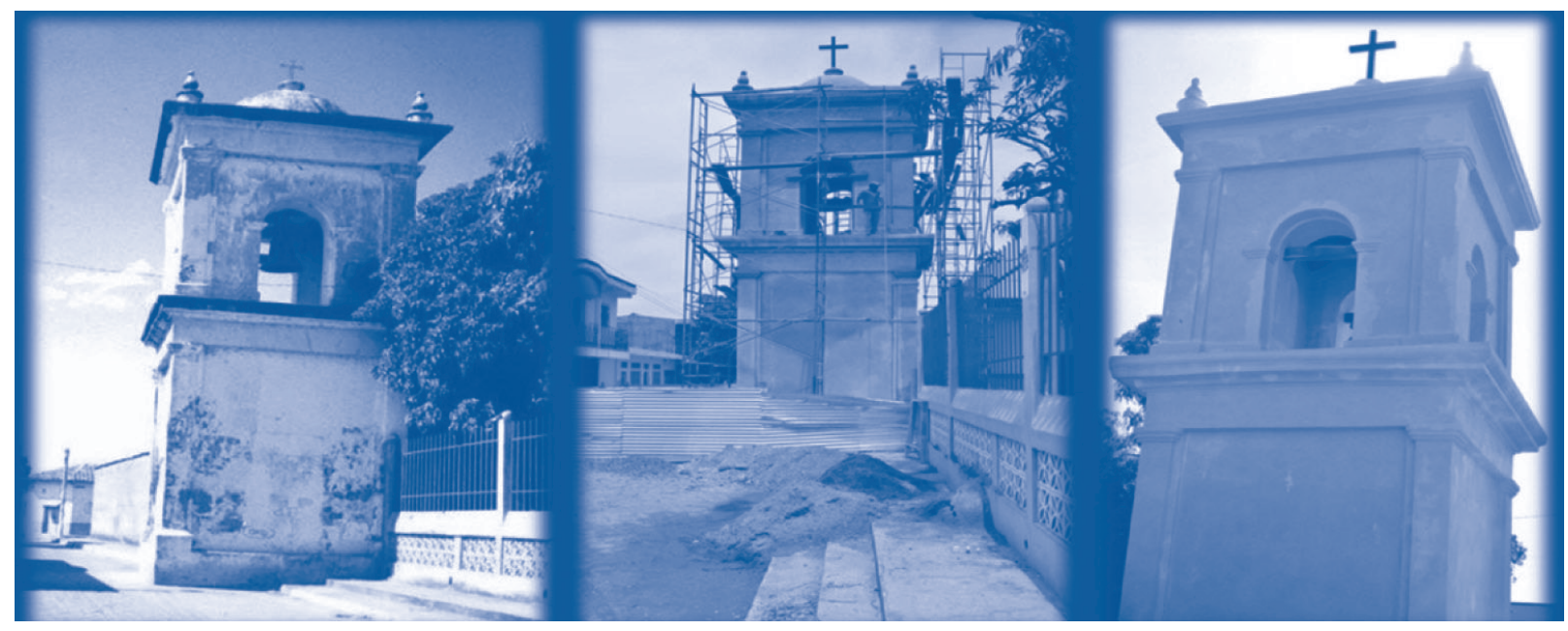

Figura 1.

Campanario Parroquia de Santiago Nonualco, que data del año 1835.

Fotografías tomadas por el equipo investigador. Año 2014.

Para Ibarra (2001), esta población de Santiago Nonualco era muy antigua; y a más de 152 años de su fundación, la población pidió terrenos, como ejidos; dichos ejidos cuentan con 38 caballerías de terrenos fértiles dedicados a la siembra de granos básicos y bosques de madera.

Su población está compuesta por mulatos y naturales, de los cuales el primer grupo en su mayoría se dedica a las artes y la agricultura y los segundos a la labranza de granos y panela. En el año de 1818 se reporta un incendio a causa de una revolución de indígenas.

\section{El génesis de la religión}

El equipo de investigación enfocó el análisis de la religiosidad y espiritualidad, así como todas aquellas prácticas y argumentaciones teóricas que son asumidas y proyectadas a niveles individual y colectivo, en donde lo tangible e intangible codifica el sentido del pertenecer y del ser, que linda entre lo mágico, religioso y profano, en el municipio de Santiago Nonualco; y en ese sentido es que se fundamenta el génesis de la religión, que está inherente en toda sociedad. Por lo que se puede afirmar que 
la religión constituye una de las expresiones socioculturales consideradas como universales, existentes en cada cultura, sin importar en qué contexto histórico se pretenda hablar $\mathrm{o}$ indagar.

Kottak (1997) señala que los orígenes de la religión, en cuanto a establecer cómo, cuándo, dónde y por qué nació son diversos, es decir, existe una serie de propuestas especulativas que hablan de su posible génesis.

Esta percepción lo llevó a considerar y decir, sobre la religión, que en las sociedades pasadas, al igual que en las contemporáneas no industriales, se desarrollaba una intriga por "la muerte", "los sueños" y "el trance". Concretamente, Tylor dice que, en la fase del sueño y el trance, los sujetos experimentan una forma de "animación suspendida"; al momento de despertar recuerdan las imágenes del mundo de los sueños. Con esta analogía, Tylor concluye que los intentos de buscar una respuesta a lo vivido o experimentado en los sueños y el trance llevó a los primeros humanos a considerar que el cuerpo humano estaba habitado por dos entes, uno activo durante el día y el otro durante la etapa del sueño y el trance (doble o alma). Esto quiere decir que, cuando el doble abandona de forma permanente el cuerpo, la persona muere. Justamente en esta etapa de la muerte se desarrolla la partida del alma.

Cuando Tylor relaciona esta trilogía entre sueños, trance y muerte, tiene como base cohesionadora de esta trilogía el término latino ánima, que hace referencia a alma. A estas formas o mecanismos de creencias, Tylor las llamó animismo (Kottak, 1997, p. 83).

Es importante recordar que Tylor, vivió en un contexto donde estaba en boga el evolucionismo unilineal. Esta influencia llevó a Tylor a proponer un proceso evolutivo en la religión; su estructura unilineal inicia con la etapa del animismo, luego pasa al politeísmo y culmina con el monoteísmo. Entonces, la religión es una forma o mecanismo de explicar todas aquellas cosas que sucedían y ameritaban darle una explicación concreta, esto conforme surgía la ciencia.

Al establecerse la dualidad existente entre la religión y la ciencia, se obtiene otra forma de poder dar respuesta a una serie de sucesos con íntima vinculación entre lo material y lo inmaterial, creencias y prácticas (Mair, 1994, p. 204).
Dentro de la concepción evolucionista se destaca la figura de James Frazer, quien, retomando el esquema de los tres estadios de comte, desarrolló un método evolucionista para explicar el proceso de tres estadios que había sufrido la religión. Según este método, la religión había cursado por la magia hacia la religión y de esta hacia la ciencia (Duch, 2001, p. 37). Otra de las teorías, fundamentadas en el evolucionismo es la de John Lubbock, quien consideraba que la evolución religiosa de la humanidad había iniciado desde una situación que él califico como "arreligiosa" hasta llegar a las grandes religiones históricas, responsables de elaborar sistemas dogmáticos y morales (Ibídem, 2001, p. 38).

Malinowski sostiene que la magia es una expresión de praxis basada en la confianza del hombre en poder dominar la naturaleza de modo directo. Dicha relación de dominio sobre el control de la naturaleza merece considerarse a la magia como pariente de la ciencia. Sin embargo, una distinción importante para Malinowski (1993) es la siguiente:

La ciencia nace de la experiencia, la magia está fabricada por la tradición. La ciencia se guía por la razón y se corrige por la observación; la magia, impermeable a ambas, vive en una atmósfera de misticismo. La ciencia está abierta a todos, es decir, es un bien común de toda la sociedad; la magia es oculta, se enseña por medio de misteriosas iniciaciones y se continúa en una tradición hereditaria 0 , al menos, sumamente exclusiva. Mientras que la ciencia se basa en la concepción de ciertas fuerzas naturales, el hontanar de la magia es la idea de un poder místico e impersonal en el que cree la mayor parte de los pueblos primitivos (p. 4).

En su trabajo, Malinowski contrapone la tradición con la experiencia, el bien común y lo exclusivo; todo ello relacionado con el poder llamado mana. El mana y no el animismo es la esencia de la "religión preanimista", y a la vez constituye la esencia de la magia que, de tal modo, resulta radicalmente diferente de la ciencia (Malinowski, 1993 , p. 4). Por lo tanto, la religión y la magia no solo explican o dan respuesta a cosas, sino que ayudan a los sujetos a alcanzar metas. También son utilizados para el dominio 
de los sentimientos. Al respecto, Kottak (2002) sostiene lo siguiente:

La magia y la religión no solo representan en su funcionalidad algo solo ligado a la parte cognitiva de los sujetos, sino a las emociones. Las creencias y prácticas sobrenaturales pueden lograr reducir la ansiedad. La magia puede disipar las dudas que son resultado o están más allá del control humano. Similarmente, la religión logra en gran medida que los sujetos puedan enfrentarse a la muerte y superar las crisis vitales. Cuando los sujetos se enfrentan a la incertidumbre $y$ al peligro, según Malinowski, buscan o recurren a la magia; la magia se utiliza para establecer control, y la religión nace de las tragedias reales de la vida humana, ella (la religión) ofrece alivio emocional cuando los sujetos se enfrentan a una crisis.

Las creencias son muy importantes para Tylor, más que los actos (Mair, 1994, p. 206). Esta aseveración de Tylor indica la importancia de lo cognitivo, o lo que se produce cognitivamente para manifestarse en los actos que los sujetos desarrollan ante circunstancias de ansiedad; pasajes vividos o manifestados en los procesos transitorios de los ritos de paso; es decir, la ansiedad manifestada en escenarios previos a los ritos de paso y durante este proceso (Kottak, 2002, p. 237). En cambio, la creencia y práctica, fe y obras (en términos teológicos), son importantes o esenciales para la religión, y ella no puede existir sin ambas. Aunque Frazer ratifica que no es necesario que la práctica religiosa adquiera siempre la forma de un ritual (Frazer, 1981, pp. 76-77).

Sin embargo, Harris (1999, p. 179), citando a Edmund Leach, dice que "la magia, la religión y la ciencia no son nada más que teorías del pensamiento, y comparten la asociación de pensamientos sobre pensamientos, ideas sobre ideas".

\section{Una perspectiva de la antropología de la educación}

La investigación se realizó en tres etapas. La tercera tuvo a su base el socializar y empoderar, por medio de la producción de una cartilla lúdica y relatores o cuentacuentos, a los estudiantes de seis centros educativos del municipio de Santiago Nonualco; fueron los de primaria, los cuales reconstruyeron las leyendas, costumbres y tradiciones de los santiagueños y después ellos mismos coloreaban con crayolas en las cartillas proporcionadas por el equipo de investigación.

El accionar de empoderamiento era muy interesante, dado que cada cartilla contenía cuatro cuentos y leyendas, de los cuales el equipo desarrollaba solo uno por grado. Y fueron los profesores los que se comprometieron en dar seguimiento al esfuerzo durante las clases de Ciencias Sociales.

Lo anterior se desarrolla en un marco que sostiene que en cada sociedad construye sus paradigmas a partir del modelo económico que impera. La Antropología, como ciencia especializada del estudio del ser humano en sus dimensiones universales, generales y particulares, construye y direcciona puentes entre la comunidad y la ciencia a partir de los procesos de investigación sistemática. En dichos procesos se analizan los diferentes ámbitos económicos, políticos, religiosos y culturales, que dinamizan la sociedad en sus diferentes estratos, de los cuales se retoman los postulados de Franz Boas sobre cultura y personalidad, como un elemento de análisis entre la colectividad y la individualidad del ser humano.

Desde la antropología cultural se define como endoculturación aquellos procesos mediante los cuales el ser humano aprende la cultura y la transmite a través de generación a generación (Kottak, 2002:58).

Es evidente que el ser humano construye sus paradigmas desde la etapa preescolar, los cuales se vuelven sus primeras referencias del mundo en el que va a coexistir con las demás especies, animales y vegetales, dentro de las condiciones que le ofrece el entorno natural muchas veces intervenido y modificado por el ser humano.

Los hechos históricos sobre los conflictos sociales a escala global también han incidido en el desarrollo del pensamiento de la antropología cultural y, por ende, de la antropología de la educación, tal como menciona Marvin Harris (1999) en el siguiente fragmento. 
En el intervalo de las dos guerras mundiales, la tendencia individualizadora del particularismo histórico coincidió e interactuó con las doctrinas de Sigmund Freud. A primera vista, el psicoanálisis y la antropología boasiana parecen tener muy poco en común. Freud era esencialmente decimonónico. Su teoría era un magno esquema a gran escala, evolucionista, materialista y determinista: o sea, justo de la clase que más condenó Boas en sus ataques contra el método comparativo. [...] Más en la perspectiva boasiana había una predisposición favorable que pasaba por encima de esto. Boas llevaba años defendiendo que la antropología cultural tenía que ser el estudio de la vida mental del hombre, y nadie podía negar que Freud hubiera abierto más caminos para penetrar en la mente humana que todos sus predecesores juntos.

El poder dinamizador de la cultura ejerce una influencia directa e indirecta en la construcción de la personalidad del ser humano. Científicos como Sigmund Freud y Franz Boas se enfrentaron en el análisis del ser humano, tanto en sus contextos individuales como los colectivos, dando de esta manera paso a la dicotomía entre la cultura y la personalidad.

Siguiendo en el análisis de Harris (1999), se cita textualmente como sigue:

Con el tiempo, la tendencia al mentalismo y al estudio de lo individual le hizo que pasara por encima del fisicalismo ${ }^{2}$ de Freud, aunque ello no ocurrió antes de que las dos escuelas sufrieran drásticos cambios: los freudianos renunciaron a su evolucionismo y sustituyeron sus complejos instintivos universales por el relativismo cultural, mientras que los boasianos por su parte dejaron a un lado su insistencia en la historia y en la difusión. EI resultado podría llamarse la versión americana del funcionalismo sincrónico: cultura y personalidad.
La cultura y la personalidad son la materia prima en el génesis de la antropología de la educación, ya que retoma los planteamientos teóricos sobre la individualidad del ser humano y cómo la sociedad, a través de los valores presentes en la familia, incide en los procesos cognitivos que, a su vez, están presentes en los procesos de enseñanzaaprendizaje, en los cuales intervienen los mecanismos de cambio cultural, esquematizando las relaciones sociales en el llamado préstamo entre culturas.

En ese sentido, según García \& Pulido (1994), la antropología de la educación tiene sus orígenes en el siguiente contexto:

El interés de los antropólogos por la educación durante dos décadas, a partir de 1930. Un considerable número de antropólogos, sobre todo estadounidenses, escribieron sobre aspectos explícitamente relacionados con la educación, aunque ya en 1904 y 1905 Hewett escribiera críticamente acerca de la restringida naturaleza de los planes de estudio, y reconociera la amplia perspectiva de la antropología.

Los planes de estudio generados a partir del sistema educativo, históricamente en El Salvador, han respondido a modelos heredados de otros países, entre ellos chile y Colombia, los cuales responden a otras realidades que la salvadoreña; dichos planes de estudio han sido estructurados bajo el interés de la economía global, en donde los países del primer mundo imponen sus formas de comprender el desarrollo, irrespetando las características identitarias de los países de la periferia o del "tercer mundo", ${ }^{3}$ los que, por tener marcada desventaja económica, deben de asumir los acuerdos tomados por sus jefes de Estado ante la comunidad internacional.

Siguiendo el análisis sobre la perspectiva de la antropología de la educación, según García y Pulido (1994), nos dice: "Para Herkovits los seres humanos son lo que son por los

\footnotetext{
Teoría defendida por algunos filósofos neopositivistas según la cual el lenguaje científico debe emplear términos que se refieran a la realidad física, o que puedan ser traducidos en dichos términos sin pérdida de significado. El fisicalismo tiene como fundamento una tesis ontológica: sólo existe la realidad espacio-temporal, la realidad física; a partir de esta tesis ontológica básica no resulta extraña su conclusión de que único lenguaje con sentido es aquél que se refiere a cosas físicas, sus propiedades y comportamientos.

3 Término peyorativo que hace referencia nada más a la desigualdad entre los países latinoamericanos que tienen diferentes realidades en cuanto al capital económico y la distribución de la riqueza.
} 
factores de enculturación, que incluyen a todos los aspectos de la experiencia de aprendizaje que distinguen al hombre de otras criaturas".

Es evidente que en las primeras etapas de vida en el ser humano se construyen o se afincan las nociones de las vidas individual y colectiva, ambas se unen para dar paso a las cosmovisiones o a los imaginarios colectivos que el ser humano adopta, expresa y reproduce en la vida social a través del tiempo; es ahí que desde esa perspectiva la presente investigación-acción aporta a esa construcción sociocultural de los santiagueños.

\section{Sobre los paradigmas de las Ciencias Sociales en "la teoría de la práctica"}

El enfoque de la cultura conocido como "teoría de la práctica" (Ortner, 1984) reconoce que los individuos dentro de una sociedad o cultura tienen diversos motivos e intenciones, y diferentes grados de poder e influencia. Tales contrastes pueden asociarse con el género, la edad, la etnicidad, la clase y otras variables sociales (Kottak, 2011).

La teoría de la práctica centra su atención en cómo un grupo tan diverso de individuos influye y transforma el mundo en el que vive mediante sus acciones y prácticas; y reconoce una relación recíproca entre cultura e individuo.

Así mismo, aparece un nuevo término bajo los enfoques procesuales de la antropología cultural: agencia, el cual se refiere a las acciones de los individuos, solos y en grupos, que crean y transforman la cultura (Ibídem, 2011).

Bajo enfoque procesual y teoría-práctica, como parte de los nuevos paradigmas en la antropología sociocultural, se puede establecer cómo las relaciones en el ámbito intergeneracional entre los(as) santiagueños(as) han ido cambiando con el transcurrir de los años en la localidad del municipio. Así mismo, bajo este enfoque se puede apreciar cómo la tradición oral, al ser retomada en los procesos de socialización y devolución de los resultados obtenidos en el proceso de investigación, fortalece el imaginario colectivo en sus identidades y proyecciones a futuro en los ámbitos económicos, políticos, sociales y culturales, en donde la religiosidad y la ritualidad están inmersos en la cotidianeidad de Santiago Nonualco.

\section{Las huellas del pasado guían los pasos en el presente. (Una metodología inédita)}

Como ya se ha mencionado anteriormente, el equipo de investigación utilizó la metodología cualitativa-etnográfica, con un enfoque de investigación-acción participativa (IAP) Según Galindo Cáceres (1998), indica

que incluye en el proceso de investigación su porqué y el para qué; sus sentido y objetivo: la transformación con miras a un mejoramiento de una calidad de vida; con miras a que una colectividad tenga mayor control y autogestión sobre sí misma [...] exige la participación consciente, reflexiva y activa de los destinatarios y destinadores de la acción [...] la IAP propone integrar conocimiento popular y conocimiento científico, está abierta a cualquier tipo de percepción de la realidad y de las prácticas sociales. Todo puede ser sujeto de análisis y de reflexión. Sólo entendiendo y aprehendiendo el conocimiento popular con toda su complejidad podemos acceder al conocimiento científico de lo social [...] La IAP es, además, una investigación de la comunicación, puesto que incluye necesariamente la reflexión, el diálogo y el consenso, y la acción colectiva constante, y trabaja, por tanto, con relaciones (estructurales, intersubjetivas, causales, históricamente determinadas, pero a la vez constructoras del sujeto social, interculturales, intraculturales, entre otras). En la investigaciónacción participativa no se estudian los problemas por separado, sino en su dimensión interrelacional e histórica.

No obstante la importancia argumentativa sobre el método de la IAP, Mercado (2002) se refiere críticamente al método de la siguiente manera:

Varias observaciones críticas se han formulado a quienes participan de este método, además de la escasa difusión escrita de los resultados encontrados, prácticamente no se cuenta con la información sobre el sustento, el tipo y las modalidades y las características de las estrategias empleadas por quienes participan en el proceso 


\section{[...] tampoco cuenta con datos suficientes} sobre ventajas y obstáculos de la participación comunitaria en este tipo de investigación, ni de los cambios logrados empleando esta vía, como tampoco de sus fracasos (p.15).

Muy a pesar de la crítica que algunos autores hacen del método, el equipo de investigación ve una oportunidad en su aplicación, dado que pondera el acierto de los resultados, no quedándose solamente en la elaboración de informes finales y en publicaciones de revistas, sino más bien proyecta, gracias a las bondades del método IAP, la acción de la transmisión y la transformación de los valores de la identidad sociocultural en el municipio de Santiago Nonualco.

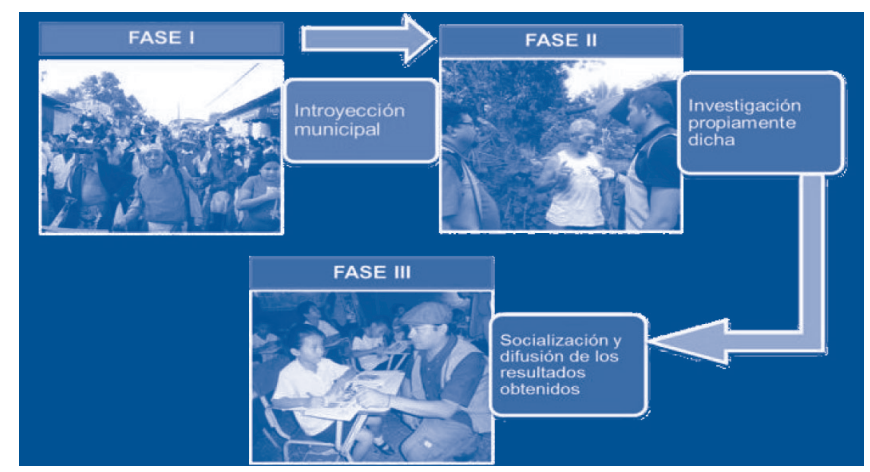

Figura 2.

Proceso metodológico en sus tres fases. Propuesta de elaboración propia.

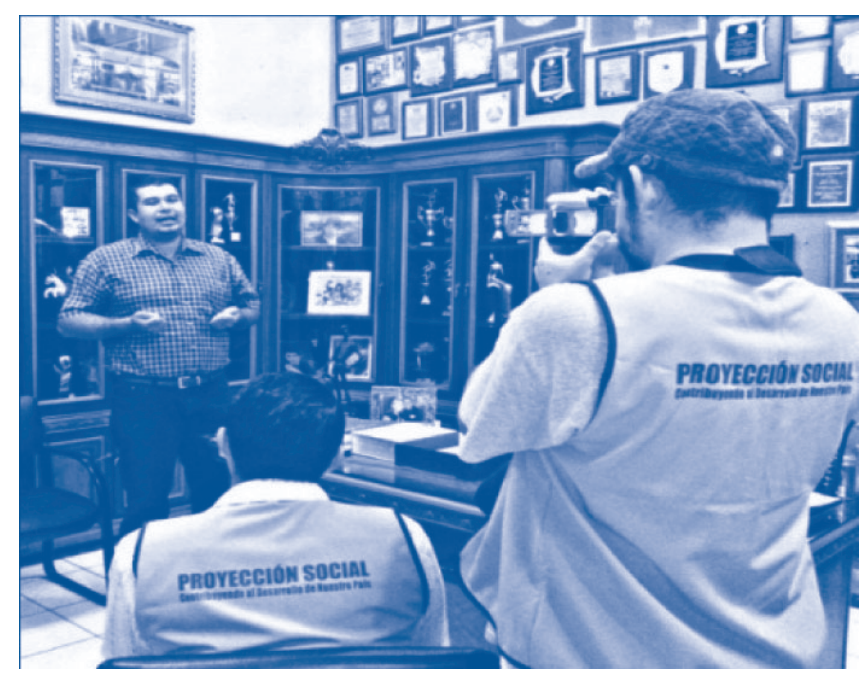

Figura 3.

Entrevista guiada, realizada por el equipo investigador a Lic. Héctor Guatemala, Responsable de la Unidad de Recursos Humanos de la Alcaldía Municipal de Santiago Nonualco.
En tanto, el proceso de investigación-acción se estructuró metodológicamente como se explica a continuación.

Entre los hallazgos y los impactos más notables se pueden mencionar los siguientes: sistematización de leyendas, mitos, tradiciones y costumbres del municipio de Santiago Nonualco, entre los que se destacan la leyenda del Muluz y el cuento de don Juan culo-quemado. Como impactos importantes se destacan, en la fase de socialización y difusión, la producción y difusión de los resultados de la investigación en un libro que se distribuyó en las bibliotecas de los centros de estudios del municipio, así como el impulso de jornadas lúdicas en las que, por medio de una cartilla para colorear, los estudiantes conocieron y discutieron la cotidianidad religiosa y espiritual de su municipio.

\section{La metodología de la investigación-acción en tres momentos}

\section{La introyección municipal}

Sumergirse en los pensamientos de la población santiagueña ha sido un proceso muy complejo que permitió un registro de cada cosmovisión, que vuelve a los santiagueños(as) únicos e incomparables con los demás pobladores de la microrregión de los nonualcos.

En ese sentido, la labor del equipo investigador se ha nutrido en cada etapa, redescubriendo la historia local y espiritual del municipio, y cómo estas han incidido tanto de manera directa como indirecta en los municipios con los que comparte límites geográficos, así como una historia en común, tal como se suscitó en el pasado mesoamericano, cuando los pueblos originarios establecieron mecanismos de intercambio y préstamos, a través de las redes de comunicación y comercialización, tanto de la cultura material como de la inmaterial.

Lo anterior ha favorecido el mantener, en períodos de conflicto étnico, las alianzas duraderas. Dichas alianzas distinguen a los nonualcos entre sí, ya que las pautas sociales diseñan los códigos en el ámbito lingüístico, que configuran el habla y los pensamientos de sus pobladores, quienes en sus núcleos familiares y sociales establecen las relaciones 
de parentesco, y por lo tanto sus códigos morales en donde la etnicidad esquematiza el perfil que guía las normas sociales entre sus integrantes. Cada pensamiento expresado en la etapa del diagnóstico municipal en Santiago Nonualco integra los mecanismos que posteriormente diseñaron los pasos que se tenían que seguir en la investigación en proceso, la cual se concibe como la segunda etapa, derivada de la etapa inicial.

\section{La investigación en su proceso de sistemati- zación}

En esta etapa el equipo investigador aplica sus conocimientos previos, uniéndolos con los nuevos aprendizajes generados en cada visita realizada al municipio. Se contrastan las teorías que se abordan en la antropología de la religión y en la simbólica, para descodificar cada pensamiento en la etapa de interpretación de datos, los cuales previamente han sido analizados para sus análisis comparativos.

Cada análisis conlleva una carga de subjetividades, de las cuales el investigador o investigadora difícilmente se escapa de su pensamiento pre-configurado. Tal como sucede en Latinoamérica, en donde prevalece hasta la fecha el pensamiento occidental, marcando los juicios de valor cuando se trata de legitimar cada elemento expresado en la religiosidad que ha resultado del sincretismo heredado desde la Conquista hasta la actualidad en un mundo global.

Cada práctica religiosa está cargada de las fes individual y colectiva de sus pobladores, quienes en diferentes espacios de la sociedad expresan su devoción ante lo considerado, sobrenatural, mítico, mágico y religioso. Tal como se suscitó en el pasado mesoamericano, en donde los pueblos originarios establecieron mecanismos de intercambio y préstamos, a través de las redes de comunicación y comercialización, tanto de la cultura material como de la inmaterial.

Lo anterior ha favorecido el mantener, en períodos de conflicto étnico, las alianzas duraderas. Dichas alianzas distinguen a los nonualcos entre sí, ya que las pautas sociales diseñan los códigos a nivel lingüístico, que configuran el habla y los pensamientos de sus pobladores; estos estable- cen en sus núcleos familiares y sociales las relaciones de parentesco y, por lo tanto, sus códigos morales en los que la etnicidad esquematiza el perfil que guía las normas sociales entre sus integrantes.

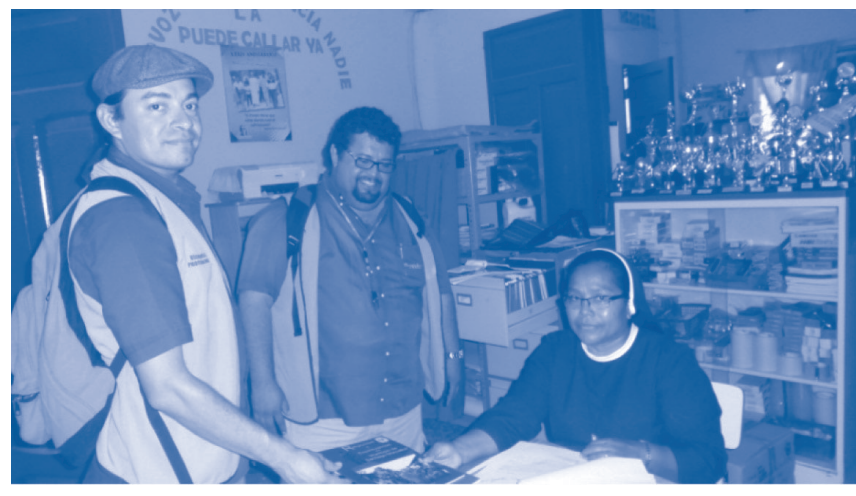

Figura 4.

Entrega de muestrario y cartilla lúdica a la directora de Complejo Educativo Católico "Fray Engelberto Malissori", por parte de los licenciados Carlos Osegueda y Miguel Ángel Hernández Vásquez. Fotografía tomada por María Antonieta Vásquez, el día 6 de junio de 2014.

\section{La difusión y empoderamiento de los resulta- dos obtenidos en la investigación-acción}

Para el desarrollo de esta tercera etapa, se editaron y diseñaron dos materiales a de texto para realizar la etapa de socialización y devolución, el cual consiste en un muestrario y una cartilla lúdica, ambos para ser reproducidos y entregados tanto a los expertos culturales, instituciones estatales (alcaldía municipal y Casa de la Cultura), religiosas (Iglesia católica e iglesias evangélicas) y centros escolares del casco urbano.

Para iniciar con el proceso de socialización, se establecieron coordinaciones en el ámbito interinstitucional, mediante la municipalidad, para hacer la entrega oficial de los documentos generados a partir de la investigación de campo; dicha entrega se realizó en un evento muy institucional en el que participaron representantes de la autoridades de la alcaldía municipal, Casa de la Cultura, región nonualca; de las iglesias, tanto católica como cristianas evangélicas; directores de centros escolares y, por supuesto, de la Universidad Tecnológica de El Salvador. 
Para lograr el objetivo propuesto de la etapa final, en lo referido a la socialización y empoderamiento en el ámbito intergeneracional de los habitantes del municipio de Santiago Nonualco, se aplicó la técnica de la narrativa, la cual consiste en asumir el papel de cuenta cuentos, en donde los futuros antropólogos(as) aplican por medio de la cartilla lúdica la reconstrucción de las diferentes leyendas del municipio de Santiago Nonualco.

\section{A manera de conclusión general}

El municipio de Santiago Nonualco tiene gran relevancia por sus accionar religioso y espiritual, que en la actualidad, mantiene una diversidad sociocultural que se manifiesta, especialmente, en los mitos, costumbres, tradiciones, leyendas y en su práctica religiosa y espiritual, que con el decidido apoyo e intervención de las autoridades municipales, referentes promotores y gestores de la cultura local, entre ellos la casa de la cultura, centros escolares y grupos religiosos, consolidan en el imaginario colectivo y en el desarrollo de su municipio de forma sustentable y sostenible la identidad de los santiagueños, que remoza o contribuye desde lo local a una escala nacional las identidades culturales de las salvadoreñas y salvadoreños.

\section{Agradecimientos}

A la Universidad Tecnológica de El Salvador por permitir que el cuerpo docente y los estudiantes de la Escuela de Antropología lograran culminar este proceso de investigación.

A los informantes claves en el municipio de Santiago Nonualco; mención especial a la Licda. Evelyn Canales, que fue nuestra promotora y gestora de esfuerzos logísticos en el municipio.

Al equipo de investigación por ser incondicional al esfuerzo de investigación.

\section{Referencias}

Alvarado, R. (1995). Estudio Monográfico del municipio de Santiago Nonualco. Santiago Nonualco: Alcaldia de Santiago Nonualco.

Alvarenga, P. (2006). Cultura y Ética de la Violencia. El Salvador 1880-1932 (2a ed.). San Salvador, El Salvador: DPICONCULTURA.

Anderson, T. R. (2001). El Salvador,1932. San Salvador, El Salvador: DPI-CONCULTURA.

Barón Castro, R. (2002). La Población de El Salvador. San Salvador, El Salvador: DPI-CONCULTURA.

Barraza Ibarra, J. (2001). La Gesta de Anastasio Aquino (Una aproximación histórica). San Salvador, El Salvador: Multilibros.

Barraza Ibarra, J. (2004). Historia de la Economía de la Provincia del Salvador desde el Siglo XVI hasta nuestros días (Vols. I,II y III). San Salvador, El Salvador: Multilibros.

Browning, D. (1998). El Salvador,la tierra y el hombre (4a ed.). (P. Gasteci, \& A. Ramírez C, Trads.) San Salvador: DPICONCULTURA.

Cardenal, R. (2001). El Poder Eclesiástico en El Salvador, 1871-1931. San Salvador, El Salvador: DPI-CONCULTURA.

Domínguez Sosa, J. (1964). Ensayo histórico: sobre las tribus Nonualcas y su caudillo Anastasio Aquino. San Salvador: MINED.

Duch, L. (2001). Antropología de la religión. Barcelona: Herder.

Galindo Cáceres, L. J. (1998). Técnicas de investigación en sociedad,cultura y comunicación (Primera ed.). (M. Á. Calderón Reyes, Ed.) México D.F.: Pearson Educación.

García Castaño, J., \& Pulido Moyano, R. A. (1994). Antropología de la Educación. Madrid: Eudema.

Harris, M. (2001). Antropología cultural (Primera ed., Vol. Tercera reimpresión). Madrid: Alianza Editorial.

Hernández Sampieri, R., Fernández Collado, C., \& Baptista Lucio, M. (2010). Metodología de la investigación (Quinta ed.). México, D.F., México: McGraw-Hill. 
Kottak, C. P. (2011). Antropología cultural (Decimocuarta ed.). (J. Mares Chacón, Ed., \& V. Campos Olguín, Trad.) México: McGraw Hill/INTERAMERICANA.

Mair, L. (1994). Introducción a la antropología social. Madrid: Alianza.
Malinowski, B. (1993). Magia, ciencia y religión. Barcelona: Planeta -Agostini.

Mercado Martínez, F. J. (2002). Investigación cualitativa en América Latina: perspectivas críticas en salud. Internacional Journal of Cualitive Methods, 13. 